\title{
Factors Affecting Student Persistence into Athletic Training Programs
}

Heather Hudson

Baylor University, sellatc05@yahoo.com

Valerie Herzog

Weber State University, ValerieHerzog@weber.edu

Follow this and additional works at: https://nsuworks.nova.edu/ijahsp

Part of the Medicine and Health Sciences Commons

\section{Recommended Citation}

Hudson H, Herzog V. Factors Affecting Student Persistence into Athletic Training Programs. The Internet Journal of Allied Health Sciences and Practice. 2019 Jan 01;17(2), Article 6.

This Manuscript is brought to you for free and open access by the College of Health Care Sciences at NSUWorks. It has been accepted for inclusion in Internet Journal of Allied Health Sciences and Practice by an authorized editor of NSUWorks. For more information, please contact nsuworks@nova.edu. 


\title{
Factors Affecting Student Persistence into Athletic Training Programs
}

\begin{abstract}
Purpose: The purpose of this study was to examine the factors that contribute to student persistence and gauge prospective athletic training students' perceptions of experiences that contributed to their persistence. Method: The Athletic Training Student Persistence-Revised Survey was developed to gather data about program attributes, social, academic, clinical integration, and program commitment. Institutional demographics, program demographics, and program attributes were collected during interviews. Surveys were administered online through SurveyMonkey. Survey data were returned anonymously by designated contact persons (Athletic Training Program Directors or Clinical Education Coordinators) for all freshmen prospective athletic training students enrolled in the athletic training introductory course/s. Descriptive statistics and non-parametric differences and correlations were calculated. The inductive process was used in coding open-ended data. Results: The Mann Whitney U test and Spearman Rho analysis demonstrated significant results. Program attributes along with clinical integration had the weakest correlations ( $r=-0.36$ and $r=-0.32$, respectively), while academic integration and program commitment had the strongest $(r=-0.58$ and $r=-0.76$, respectively). No predictive variables were found. Qualitatively, persisters and non-persisters managed the pre-application period differently. Additionally, the rapport between athletes and athletic trainers serving as preceptors, the relationships between prospective athletic training students and extant athletic training students, and the mentorship displayed by athletic training students were all contributors to persistence. Conclusions: Communication between the athletic training program director and prospective athletic training students is vital, but the core of the study revealed that what transpires during clinical observation hours, within the introductory course/s, between athletic trainers and athletes, and between athletic training students/preceptors and prospective athletic training students are of even greater importance. The findings demonstrated that decisions to persist are the result of all parties and components associated with the athletic training program, not just one.
\end{abstract}

\footnotetext{
Author Bio(s)

Heather Hudson, EdD, LAT, ATC, is a Clinical Associate Professor of Athletic Training at Baylor University.

Valerie Herzog, EdD, LAT, ATC, serves as the Graduate Athletic Training Program Director and Director of the Office of Graduate Studies at Weber State University. She is currently a Commissioner for the Commission on Accreditation of Athletic Training Education.
} 


\title{
1IVAHSP \\ The Internet Journal of Allied Health Sciences and Practice \\ Dedicated to allied health professional practice and education
}

Vol. 17 No. 2 ISSN 1540-580X

\section{Factors Affecting Student Persistence into Athletic Training Programs}

\author{
Heather Hudson ${ }^{1}$ \\ Valerie Herzog² \\ 1. Baylor University \\ 2. Weber State University \\ United States
}

\begin{abstract}
Purpose: The purpose of this study is to examine the factors that contribute to student persistence in getting into an athletic training program and gauge prospective athletic training students' perceptions on experiences that contributed to their persistence. Method: The Athletic Training Student Persistence-Revised survey was developed to gather data about program attributes, social, academic, clinical integration, and program commitment. The survey was administered to freshmen prospective athletic training students. Institutional demographics, program demographics, and program attributes were collected during interviews. Surveys were administered online through SurveyMonkey. Survey data were returned anonymously by designated contact persons (athletic training program directors or clinical education coordinators) from freshmen prospective athletic training students enrolled in the athletic training introductory course/s. Descriptive statistics, non-parametric differences, and correlations were calculated. The inductive process was used in coding open-ended data. Results: The Mann Whitney U test and Spearman Rho analysis demonstrated significant results. Program attributes along with clinical integration had the weakest correlations $(r=-$ 0.36 and $r=-0.32$, respectively) while academic integration and program commitment had the strongest $(r=-0.58$ and $r=-0.76$, respectively). No predictive variables were found. Qualitatively, persisters and non-persisters managed the pre-application period differently. Additionally, the rapport between athletes and athletic trainers serving as preceptors, the relationships between prospective athletic training students and athletic training students, and the mentorship provided by athletic raining students were all contributors to persistence. Conclusions: Communication between the athletic training program director and prospective athletic training students is vital, but the core of the study revealed that what transpires during clinical observation hours, what occurs within the introductory course/s between athletic trainers and athletes, and the relationship between athletic training students/preceptors and prospective Athletic Training students is of even greater importance. The findings demonstrated that decisions to persist are the result of all parties and components associated with the athletic training program, not just one.
\end{abstract}

Keywords: Athletic Training, retention, secondary admission process, persister, non-persister 


\section{INTRODUCTION}

Retaining students in higher education is not a new issue, but it is a very important one. Over the past several decades, there has been an increase in students starting programs of study and then leaving without degree completion. ${ }^{1}$ Low retention rates are a major concern for colleges and universities, in part, because of the financial loss (on many differing levels) accrued by the college or university when a student begins a major of study and then does not continue with it. ${ }^{2}$ Moreover, high student departure rates create an environment of instability for the institution while calling into question the quality of the programs offered by the institution. 3,4

Retaining students is also a concern for specific professional majors of study, particularly in the health professions. With an expanding job market, especially in athletic training, there has been an increased focus in meeting the demands of providing quality healthcare to patients in a variety of settings (e.g., high schools, performing arts, athletics). This demand places pressure on healthcare majors to graduate competent, entry-level practitioners. ${ }^{4}$ Therefore, admitting and retaining quality students in such programs is essential.

Seidman formally defined retention as students who remain at a particular institution until degree completion, while student persistence is a student's desire and action to progress and graduate within the system of higher education. ${ }^{5}$ Student retention and persistence have been studied from a multitude of perspectives. Psychological theories target characteristics of the student and how a certain student characteristic profile influences student persistence. The organizational perspective explains how organizational structures, behaviors, attributes, and characteristics interplay with student persistence.3,6-8 Finally, the sociological perspective delves into how the social structures and forces influence student persistence. $3,5,9-11$ Retention research has also focused on how the first-year experience influences student retention. Research suggested that the experiences students have during their first year were defining factors of student departure from an institution, especially during and after the first year. ${ }^{12-14}$ Research has revealed that interactions and experiences affect the level of integration into the academic and social systems of a particular institution, thus altering the student's level of commitment.

Within the Commission on Accreditation of Athletic Training Education (CAATE) standards, athletic training program (ATP) directors have the autonomy to freely structure the application process and program. Because of this, there is very little consistency in structuring of the first-year experience or admissions process from program to program. Graduating successful entry-level athletic trainers (ATs) begins with recruiting quality students to college campuses who will apply and ultimately major in athletic training. Since a secondary admissions process is practiced by a large number of ATPs and usually occurs sometime during the first year, ATPs should concentrate on students' first-year experiences to try to increase program enrollment through student persistence..$^{15}$ Although all professional (entry-level) AT programs will have to be at the master's degree level by 2022, institutions will have varying options in how to design or structure the program. Some may elect to be structured as $3+2$ or $2+3$ models where the undergraduate and graduate portions of the program are integrated, or as an alternative, be structured as a standalone twoyear program; both are already practiced. Either way, retention of quality undergraduate students through a five year process or through a two year process will still be very important.

It may be argued by those in healthcare and allied healthcare fields that a process to weed out students is necessary and must occur, and that most programs only want students who will succeed both academically and clinically. However, in the process of weeding out students, as practiced in athletic training by use of a secondary admissions process or pre-application processes, actions or behaviors by those associated with the process may facilitate non-persistence of those exact individuals sought after. Even though the intent of the selection process is and should be a competitive one, good students may be alienated from programs because of program attributes or ineffective pre-application structures during the student's first-year. Current admission and selection practices may undermine the effort by programs to graduate practitioners who can provide the healthcare needed for various patient populations.

Therefore, the purpose of this study was to continue the exploration of the factors that affected students' decisions to persist (i.e., apply or not apply) to athletic training programs (ATPs) by using specific components of Tinto's Interactionalist Model combined with the concept of organizational attributes/characteristics. ${ }^{9}$ There is overlap in the use of the terminology "persister." The terminology of "persister" and "non-persister" was employed by the researcher. "Persisters" were defined as prospective athletic training students who decided to apply to the ATP while "non-persisters" were prospective athletic training students who did not apply to the ATP. Young also uses the term "persister," but the context and population for which this term was used is different and refers to ATSs within an ATP and completing their degree in AT. ${ }^{16}$ Young compared the "persister" group to "dropout" or ATSs who did not persist till graduation. ${ }^{16}$ 


\section{METHODS \\ Study Design}

A mixed-methods approach was used to conduct this study. Both a survey with closed- and open-ended items and semi-structured interviews with a designated contact person, either ATP Directors or Clinical Education Coordinators (CECs), were conducted to gather data. Permission to complete the study was granted by the Institutional Review Boards at each institution. For the purpose of this study, the Athletic Training Student Persistent Survey-Revised (ATSPS-R) was used. The ATSPS-R was adapted from its original version and contained four sections. ${ }^{17}$ Section I of the survey consisted of four items related to demographics of the student including high school GPA, age, gender, and race. Section II of the survey included five construct areas of close-ended items relating to academic integration, social integration, clinical integration, program commitment, and program attributes (Table 1). A 5-point Likert scale was used, consisting of the following range: 1=strongly disagree, 2=disagree, 3=neutral, 4=agree, and $5=$ strongly agree. Section III of the survey consisted of open-ended items related to each construct area. The open-ended items sought additional information from students as to any experiences (not identified through closed-ended items) that occurred during the pre-application period that influenced their decision to persist or not persist (persisters/non-persisters respectively). Section IV of the survey included three items that ascertained whether or not the student applied to the program (served as the dependent variable), whether they understood the grade requirements needed in the required classes for admittance into the ATP, and if they met the minimum requirements for admission into the ATP. The final question was an open-ended item that sought to illicit from participants any other factors affecting their decision to apply that had not been addressed on the survey (Appendix A).

\begin{tabular}{|c|c|c|}
\hline Constructs & Survey Items & \# of survey items \\
\hline $\begin{array}{l}\text { 1. Program } \\
\text { Attributes }\end{array}$ & $\begin{array}{l}\text { This construct area was divided into three subcategories including } \\
\text { communication, perceived fairness in administration of policies and rules, and } \\
\text { student participation in organization decision making. Two items addressed } \\
\text { each subcategory. Additionally, two questions addressed student's } \\
\text { understanding of program requirements and an open-ended question allowed } \\
\text { students to articulate structural changes they would suggest. }\end{array}$ & 9 \\
\hline $\begin{array}{l}\text { 2. Academic } \\
\text { Integration }\end{array}$ & $\begin{array}{l}\text { This construct area was represented with items relating to student perceptions } \\
\text { of how well they have performed in their athletic training class/es, if they found } \\
\text { the athletic training courses to be stimulating, and their overall satisfaction with } \\
\text { athletic training as a course of study. }\end{array}$ & 6 \\
\hline $\begin{array}{l}\text { 3. Social } \\
\text { Integration }\end{array}$ & $\begin{array}{l}\text { This construct area was represented by student perceptions of the non- } \\
\text { classroom experiences with ATEP faculty, the relationships developed with } \\
\text { ATSs or observation students beyond clinical experiences and classroom } \\
\text { experiences, and how easy it was to meet and make friends. }\end{array}$ & 6 \\
\hline $\begin{array}{l}\text { 4. Clinical } \\
\text { Integration }\end{array}$ & $\begin{array}{l}\text { This construct area was represented by items relating to student perceptions } \\
\text { of how challenging and interesting the clinical observation experience has } \\
\text { been for them. In addition, items relating to interactions with peers and clinical } \\
\text { instructors (preceptors) were rated by participants influence on your decision } \\
\text { to apply or not apply to the athletic training education program. }\end{array}$ & 6 \\
\hline $\begin{array}{l}\text { 5. Program } \\
\text { Commitment }\end{array}$ & $\begin{array}{l}\text { This construct area was represented by items related to student commitment } \\
\text { to athletic training as a major and commitment to a particular ATEP. }\end{array}$ & 3 \\
\hline
\end{tabular}

Because of travel limitations associated with the location of each institution, the interviews were conducted by phone. The interviews were semi-structured and occurred between the researcher and the contact person from each institution. Semistructured interviewing was used to obtain specific information while also facilitating in-depth development of certain information. The researcher devised specific questions to ask, but the technique allowed for deviation from those questions when necessary. Deviation afforded participants the opportunity to explain their answers further (depth-probing) and provided the researcher a clearer understanding. ${ }^{18}$ Interview questions were designed to gather information regarding institutional demographic information, program demographics such as the number of students who typically apply and how many are typically accepted, program characteristics such as admission requirements and type of introductory course/s, and program attributes such as how program requirements were typically communicated to the students and how observation experiences were determined and assigned (Appendix B). Information collected from the interviews served as a reference and was compared to certain student participant 
responses.

\section{Participants}

The subject population for this study included all freshmen prospective athletic training students (ATSs) ( $\mathrm{n}=111$ ) who were enrolled in the athletic training introductory course/s at three institutions as well as the designated contact person, either the ATP director $(n=2)$ or the CEC $(n=1)$. Fifty-nine participants $(n=59)$ of 111 participants $(n=111)$ completed the survey for a response rate of $53 \%$. All participants were over the age of 18 years $(\bar{X}=18.53, \mathrm{SD}=.65)$. A majority of participants were female $(62.7 \%)$, while $33.3 \%$ were males. Likewise a majority of the participants were (81.4\%) were Caucasian. Additional descriptive and statistical analyses were conducted of survey responses while controlling for the question "I am applying or I am going to apply to the ATP" which was a yes or no question. Five participants did not answer this question at all; therefore, information from those surveys was not used. Accordingly, a total of $54(n=54)$ of the surveys were usable for a response rate of $48.6 \%$ (Table 2).

\begin{tabular}{|c|c|c|c|c|c|c|c|c|c|}
\hline \multirow[t]{2}{*}{ Applied } & \multicolumn{3}{|c|}{ Age } & \multicolumn{2}{|c|}{ Sex } & \multicolumn{4}{|c|}{ Race } \\
\hline & 18 & 19 & 20 & Male & Female & Caucasian & Hispanic & $\begin{array}{l}\text { African } \\
\text { American }\end{array}$ & Other \\
\hline Yes(s) & 23 & 16 & 2 & 13 & 28 & 33 & 3 & 4 & 1 \\
\hline $\mathrm{No}(\mathrm{s})$ & 8 & 2 & 3 & 6 & 7 & 12 & 0 & 1 & 0 \\
\hline Total & 31 & 18 & 5 & 19 & 35 & 45 & 3 & 5 & 1 \\
\hline
\end{tabular}

\section{Procedures}

After IRB approval was obtained at the researcher's Institution, ATP Directors of CAATE-accredited programs were contacted by phone prior to the study beginning to solicit participation. During initial conversations, the specific contact person was identified, application procedures and application deadlines were ascertained, whether IRB approval was needed from participating institutions was determined, and a follow-up interview with the contact person was secured. Only one of the participating institutions requested additional IRB approval by their own IRB. It was sought and granted.

Two weeks prior to the identified application deadlines (specific to each institution), an e-mail communication was sent to the contact person. The body of the e-mail included the purpose of the study, criteria for participation, an explanation of the importance of the study, and the intended use of the results. The e-mail also included a letter composed to the students with the same information, and a link to the student survey was added. Contact persons were asked to forward the letter with the link to all firstyear students enrolled in the introductory course/s for athletic training regardless of whether they were applying or not applying to the program. The first page of the survey included a letter of consent. Participants were informed as part of this consent that they may exit the survey at any time. Once consent was secured, the survey was displayed to the participant. Additionally, two followup e-mails were sent, one week after the identified application deadline and one week after the first follow-up e-email. The survey link for each institution was closed one week after the second reminder e-mail. Quantitative data were transferred from SurveyMonkey into SPSS for analysis.

\section{Statistical Analyses}

Content validity for the construct areas of academic, social, and clinical integration was determined through previous studies and a comprehensive literature review. Content validity, specifically as it related to program attributes, was determined through the use of content specialists. The survey was distributed to ATP directors, CECs, and students not associated with ATPs participating in the study. To test for internal consistency, a Cronbach's alpha numeric coefficient of reliability was calculated for each construct.

A Mann Whitney $U$ test was used for each independent variable to determine if there were differences between the two groups of participants (those who persist and those who do not persist) and whether or not those differences were significant. A Spearman Rho Correlation Analysis was also used to determine if a relationship existed between each of the independent variables and the dependent variable, A binary logistic regression analysis was conducted to test for predictive variables. The significance level for this study was $p<.05$.

Qualitative data were collected from five survey items. The researcher coded content from open-ended items for recurring themes among responses using an inductive process. The researcher discovered themes as they emerged through interacting with the data. ${ }^{18-21}$ Each item (which served as the overarching theme during the coding process) and the associated group were coded 
separately. For example, persisters' responses to "please explain any particular experiences that had an influence on your decision to apply" were analyzed together, while the non-persisters and their answers to the same question were analyzed. The researcher initially read through each of the responses, noting any words or phrases that consistently appeared. After the initial reading was completed, common subthemes were identified relevant to open-ended items for each of the groups. Several rounds of coding were completed until saturation was reached. Responses were then grouped and placed into the subthemes. In the reporting process, each subtheme was compared across groups noting any commonalities among the two groups and also identifying any subthemes that were unique to each group.

After permission was granted by each interviewee, phone interviews were recorded by the researcher. This was done in an effort to maintain an accurate account of the interview. Each interview concluded with the researcher asking if there was any further information the interviewee would like to disclose. Interviews were then transcribed and coded by the researcher. During the coding process of the interviews, the researcher looked for commonalities among the ATPs as well as differences. Information was used to compare program structure, admission requirements, and program attributes of each ATP.

\section{RESULTS}

\section{Quantitative Results}

The results of the Mann Whitney $U$ test showed a significant difference between the two groups with the largest difference being academic integration $(U=60.5, p<.05)$. The null hypotheses were rejected based from these results (Table 3). The binary logistic regression analysis did not reveal any predictive values of the independent variables. However, what was determined was that a relationship did exist between the two groups and each independent variable. The inclusion of the independent variable, program attributes, was in an effort to add to the already existing literature about persistence in ATPs and to determine to what degree, if any, those attributes affect persistence. It, along with clinical integration, had the weakest correlations $(r=-0.36$ and $r=-0.32$, respectively). The two strongest correlated independent variables were academic integration and program commitment $(r=-0.58$ and $r=-0.76$, respectively) (Table 4).

\begin{tabular}{lcc}
\hline \multicolumn{2}{l}{ Table 3. Mann Whitney U Test } & \\
\hline & $U$ & Sig. \\
\hline $\mathrm{PA}$ & 133.5 & $\mathrm{P}<.01^{*}$ \\
$\mathrm{SI}$ & 110.00 & $\mathrm{P}<.05^{*}$ \\
$\mathrm{Al}$ & 60.5 & $\mathrm{P}<.05^{*}$ \\
$\mathrm{Cl}$ & 153.50 & $\mathrm{P}<.05^{*}$ \\
\hline
\end{tabular}

Note: $\mathrm{PA}=$ program attributes, $\mathrm{SI}=$ social integration, $\mathrm{Al}=$ academic integration, and $\mathrm{Cl}=$ clinical integration

Table 4. Correlations Between Persistence and Construct Areas

\begin{tabular}{lcc}
\hline $\begin{array}{l}\text { I have applied or I am going to apply to } \\
\text { the ATEP }\end{array}$ & $r$ & Sig. (2-tailed) \\
\hline PA & -.359 & .009 \\
SI pos & -.405 & .003 \\
Al pos & -.580 & .000 \\
CI pos & -.320 & .018 \\
Com & -.762 & .000 \\
\hline
\end{tabular}

\section{Qualitative Results}

Program Attributes. A component of program attributes was structure of the pre-application process; therefore, the first open-ended survey item asked participants to identify anything about the structure of the pre-application period that could be changed. A subtheme that emerged and was common between the two groups related to the length of the pre-application period. However, instead of less time, persisters suggested that hours should be increased, or the pre-application period should be longer, while non-persisters suggested more time for the pre-application period would not be welcomed. 
Choose students at mid-term of the first semester so they do not have to wait a whole semester to do what they wanna do for a living. (non-persister)

I would make it simpler and within the first two class days. (non-persister)

I would like to have time or more opportunity to meet my classmates who are also observing. (persister)

Maybe bump up the clinical experience hours. (persister)

Social Integration. Social integration was represented by the interactions prospective students had with ATSs within the ATP. Persisters and non-persisters alike spoke positively about the interactions that occurred, and for many of the nonpersisters these interactions made the decision not to apply more difficult.

Well they are all easy to talk to, ask questions about the athletes that are injured. Making the whole observation part knowledgeable, and a fun experience. (non-persister)

The students were the reason that I was on the fence between staying and leaving. They were all so nice and made me feel welcome and I wanted to stay with them, but decided to change for other reasons. (non-persister)

Everyone has been really friendly, I feel like everyone really tries hard to make you feel welcome. (persister)

I went to the athletic training club and just all of the students were so kind and helpful I really appreciated it. (persister)

Additionally, mentorship provided by the ATSs within the ATP was identified by persisters as an important factor for their persistence.

The athletic training students I have met have given me heads up on what is expected in some classes and also they gave me a lot of future help for applying to the program and also classes while in the program. (persisters)

I was able to talk to a senior athletic training student and he gave me helpful tips on what to do and how to get noticed on filling out the application. He was easy to talk to about the whole process. (persisters)

Academic Integration. Academic integration is typically conceptualized by a student's grade performance and the degree of intellectual development. However, participants of this study identified academic integration in terms of challenge and content taught within the course/s. Non-persisters had positive reflections about the content and found it to be interesting and helpful in making decisions about other career choices, but cited that the amount of effort and commitment level that would be required to continue in athletic training did not really match interest level.

The amount of effort I put into the program did not reflect on how interested I really am. I am not going to apply due to my sport because they want people who give their all and I was not doing that. (non-persister)

I just realized athletic training is not what I wanted to do. I was more interested in the psychological aspect of people than the physical" and "This course will aid me in my future for an occupational therapy degree. (non-persister)

Persisters also spoke of challenge, commitment level, and content, but in a manner that was more positive and supportive of their desire to be athletic trainers. The challenge provided by the ATPs was desired and the content motivated persisters.

The positive environment and the demand of the program influenced my decision to apply to the program. I like to have a challenge and something to do every day, and I see that this program will give me both. (persister)

I was intrigued to learn about the different tapings and injuries, and I can't wait to apply them to real life athletes. (persister)

My instructor was teaching about second impact syndrome and when he had shown the video about Preston Plevretes; at that moment I really felt like this is the major for me. I want to do everything in my power to prevent that from happening to our athletes. (persister) 
Clinical integration. Clinical integration is the construct where persisters and non-persisters perceptions diverged. A difference existed among groups in how they perceived clinical integration. Non-persisters commented on the amount of time that must be invested, the commitment level, and the lack of engagement during clinical observations time, while persisters commented on the rapport and the positive relationships observed with athletes. This particular subtheme was divided into additional categories: (a) those interactions witnessed between the preceptors and athletes, and (b) the interactions between the participants and athletes. These interactions reinforced the passion that already existed for sports, in turn, strengthening the participants' desire to persist.

I have chosen not to apply because of the time I would put in and also I am not good with blood or dislocations or any other nasty injury. (non-persister)

I had too many schedule influences and I only wanted to take the major to help me become a physical therapist and if that didn't work I would be able to take an athletic training job. (non-persister)

I loved the close relationships athletic trainers had with the athletes. They knew them on a name basis, and I think it is vital to have close bonds with your patients in the athletic training room. They are comfortable talking to you and you are comfortable explaining things to them. I want to be involved in that type of field. (persister)

In my experiences I have realized that being around sports and being around athletes is definitely something I want to do. I would also enjoy helping them and improving their game. (ersister)

Additionally, persisters could envision helping others, which strengthened their desire to persist.

I know that I want to be able to help the athletic population. I love being in the athletic training room and cannot imagine doing anything else. (persister)

When I was watching an athletic training student do rehab with a basketball player, made me realize I could see myself doing that job. (persister)

\section{DISCUSSION}

Academic integration was typically viewed through GPA and how a student perceived intellectual development. This study revealed that the type of content taught within the introductory course/s was significant. The three institutions offered course/s that combined didactic and psychomotor information. The content within the introductory course/s was important in developing engagement within the classroom and to create authentic interactions between peers, teachers, and the content itself. Tinto's findings indicated that students who participated in a coordinated studies program were able to build a network of support, engage in shared learning, gain a voice, and experience a richer academic environment. ${ }^{22}$ Additionally, students' perceptions of intellectual gain and academic performance increased with participation in such a program. Research supports that academic integration leads to persistence, and qualitative results of this study underscore such research.9-10,13,22 Therefore, creating a shared and collaborative classroom environment by combining didactic and psychomotor strategies should be practiced by ATPs during the pre-application process and not be reserved for ATSs already admitted into the ATP. This concept may be of greater importantance with graduate programs choosing to practice an acclerated $(3+2$ or $2+3)$ design.

Clinical education is another area that has been studied in healthcare professions such as nursing. Research has shown that interactions during this time bear some weight as to whether students persisted with the major they chose. ${ }^{15-16,23}$ Taking into account research already conducted on clinical education and clinical integration and applying it to the clinical observation experience practiced as criteria for admittance into ATPs is a logical step. Studies have primarily looked at the interactions that occur between student and preceptor. The influence that the preceptors had on students during clinical education and the importance of modeling positive behaviors was frequently underestimated and understated. . $^{16,23-25}$

This study supported existing literature pertaining to the importance of creating a positive environment where students are immersed ${ }^{26-29}$ However, this study presented an additional perspective on clinical observation experiences as evidenced by the importance of rapport and close relationships that existed between an AT and the patients for which they cared. Many persisters in this study expressed a desire to have the opportunity to emulate those relationships. Images of helping others and establishing good rapport with patients seemed to increase persistence for this group of respondents. Participants also reported that having the opportunity to interact with and establish their own relationships with the athletes during observation experiences was key, and

(C) The Internet Journal of Allied Health Sciences and Practice, 2019 
aided in creating a positive and stimulating environment. Clinical observation experiences may be the only occasion prospective ATSs have to observe such interactions, once again supporting the role and importance the clinical observation experience plays in persistence. Again, if a program chooses to design an accelerated master's program, the observation period in terms of timing and amount may be of significant importance in students persisting.

Social interactions were identified as vital to an individual integrating into any system. ${ }^{9-10,29}$ Those interactions can either be viewed as positive or negative. Positive interactions and experiences may lead to an increase in retention rates, while negative interactions or experiences may contribute to high attrition rates at colleges and universities. ${ }^{29}$ Christie and Dinham demonstrated that different types of institutional experiences could contribute to social integration; however, the type of interactions between and among individuals was not considered. ${ }^{29}$

The current study demonstrated two effects relatitng to social interactions: 1) the type of interactions matter, and 2) ATSs can be the driving force behind the type of environment that exists within the ATPs. Persisters and non-persisters alike commented on how much the positive interactions meant to them and affected their decisions' to persist. It would seem that mentorship provided and the passion displayed by the ATSs were two of the most profound findings of this study. Utilizing current ATSs may be a way for ATPs to increase persistence and retention rates within programs.

Tinto's research included discussions about how commitment to a particular institution affected retention.9-10 Tinto suggested that the increased commitment to a particular institution typically equated to higher retention rates. Tinto explained that students held both commitment to a certain goal and to an institution. Commitment to an institution may be related directly to family tradition, or the perception of graduating with a degree from the institution or of being an integral part of an occupation. ${ }^{10}$ Quantitative analysis of this construct showed the strongest correlation to persistence. These results supported Tinto's notion that students arriving at institutions with some anticipatory commitment to a particular institution, and in this case a particular ATP, leads to persistence..$^{10}$ Additional support was provided through qualitative analysis. Multiple persisters cited that the reputation of the ATP, as demonstrated by the ATPs' high passing rates on the BOC exam and high placement rates after graduation, was a reason they decided to attend the particular institution and to apply to the ATP. Therefore, these students already came to the school with some commitment to the ATP.

Research has also demonstrated that commitment can be altered by the interactions or experiences that take place once the student was at the institution, often a result of either incongruence or isolation. ${ }^{10}$ Incongruence is considered to be where the academic and social demands do not match the student's perceptions, either too hard or not hard enough. Non-persisters may have experienced incongruence, because on multiple occasions the time commitment, effort level, and challenge were cited as reasons for non-persistence. Incongruence may have prevented the non-persisters from being properly integrated into the social, academic, and clinical systems. Persisters did not focus as much on the demand as a detractor, but rather focused more so on positive attributes of the athletic training major, such as the relationships and interactions observed and created, which potentially allowed for integration to occur socially, clinically and academically.

It should be recognized that communicating goals, expectations, and requirements of the pre-application period to prospective ATSs was noteworthy. Each institution participating in this study communicated such information beyond the CAATE standard that requires ATPs to publish requirements, expectations, etc. Each institution used the introductory course/s as a means to explain, teach, and relay information about the pre-application process and period. Two of the institutions used meetings outside of the course/s as another method to make available information needed to be successful. This is significant because both groups responded to the survey items related to communication favorably, as well as having an understanding of the admission requirements, goals, and expectations. Because both groups responded in relatively the same fashion and $75.9 \%$ of the total participants persisted into their respective ATP, it can be assumed that the ATPs did communicate well to prospective ATSs, and this was not necessarily a contributing factor to non-persistence for this study. However, institutions that may not communicate as effectively might experience decreased persistence. As athletic training programs make decisions on program design for graduate level professional programs, those programs choosing to have an accelerated program may find this informtion beneficial. And the relaying of information to prospective students may need to be even more intentional in order to retain students for a longer period of time.

Finally, Kotecha's research into nurse wastage found that different discourses existed in how nursing education and nurse learners were to be viewed. ${ }^{30}$ Overall, results showed that it was not the discourse itself that lead to either persistence or wastage but, rather, how the learner read the discourse: individuals who persisted or dropped out did so from both types of discourses, but those who persisted were able to use either discourse to positive ends. It seems that the same is true for persisters and non-persisters of this study. Persisters often viewed the components of the admissions process more positively and focused on those components

( The Internet Journal of Allied Health Sciences and Practice, 2019 
that could help them be successful and did not let other items detract or detour them from their desire to achieve their goals.

\section{LIMITATIONS}

The sample size $(n=54)$ of this study along with the disproportionate number of persisters to non-persisters who completed the survey (41 persisters and 13 non-persisters), may have contributed to the weak quantitative results. This may be a result of several factors: a) the limited number of ATP participation, b) dependence on contact person, and c) participation in the study was optional. The researcher contacted several different ATPs in an effort to increase the sample size; however, only three CAATE accredited ATPs with a secondary admissions process in the fall committed to participating. The survey instrument itself may also prove to be a limitation. It was tested for readability, validity, and clarity; however, it was adapted from its original form for the purpose of this study with the addition of the construct area of program attributes as well as open-ended survey items. Moreover, the phrasing of the open-ended survey items may have led participants in a particular direction. For example, the open-ended item addressing social integration read, "Please explain any particular experiences or interactions with other ATSs or observation students that were a strong influence on your decision to apply to the athletic training education program." Because social integration includes both interactions with faculty and students, perhaps the wording should have reflected all three groups (ATSs, other observation students, and faculty) and the use of "interactions" should have been removed.

The qualitative methodology employed also may have been a limitation. The study included the use of open-ended items and interviews with contact persons from the ATPs. The inductive process was used until theme saturation was obtained. The qualitative method does induce some researcher bias. It is a process where one reads for words, phrases, or themes that frequently emerge from data. The same information may produce different results from researcher to researcher. Since the literature indicated such variance in accepted coding procedures, the researcher of the current study elected to be the only individual viewing and coding the data.

\section{CONCLUSIONS}

There are several conclusions that can be drawn from this research study. The study confirmed existing retention research, as well as offered some new perspectives about persistence into ATPs. This was evidenced more strongly through qualitative information attained from participants, rather than the quantitative perspective. It seems that a necessary component of athletic training education is to have prospective ATSs participate in a pre-application process.

Overall, the pre-application process (introductory course/s and observation hours) gave participants the chance to experience what it would be like as an ATS within the ATP and gave them a real world perspective as to their roles and responsibilities as ATs in the future. Each group managed this process differently and developed different perspectives, and this management should be considered by those overseeing ATPs. If ATPs are practicing a pre-application process, individuals overseeing the ATPs may find information provided in this study as beneficial and helpful in facilitating persistence of prospective ATSs. Additionally, these findings might also be useful in professional master's degree programs using a $3+2$ format, where the undergraduate students are preparing to apply to and enter the master's degree program while at the same institution.

All stakeholders should understand what contributes to persistence. The study's findings demonstrated that decisions to apply to an ATP are the result of all parties and components associated with the ATP, not just one. Communication between the ATP director and prospective ATSs is vital so that expectations, goals, and requirements are clearly relayed, but the core of the study revealed that what transpires during observation hours, within the introductory course/s, between ATSs/preceptors, and prospective ATSs are of even greater importance. By understanding this, maintaining the requirements to differentiate between capable students can remain, but elimination of those capable students because of the actions or behaviors of those associated with the ATPs may be reduced, therefore retaining the prospective ATSs who are both academically strong and who also have a strong desire and affinity for working as an AT can occur. Findings of this study, could potentially be translated and considered for persistence and retention with students already admitted into ATPs, both at the professional baccalaureate and master degree levels.

\section{REFERENCES}

1. Assiter A, Gibbs RG. Teaching and training: student retention and motivation. Eur Polit Sci. 2007;6(1):79-93.

(c) The Internet Journal of Allied Health Sciences and Practice, 2019 
2. Bennett R. Determinants of undergraduate student dropout rates in a university business studies department. $J$ Furth and Higher Educ. 2003;27(2):123-41.

3. Berger J B, Braxton JM. Revising Tinto's interactionalist theory of student departure through theory elaboration. Res Higher Educ. 1998;39(2):103-19.

4. Bowman TG, Dodge TM. Factors of persistence among graduates of athletic training education programs. J Athl Train. 2011;46(6):665-71. [PMID: 22488193]

5. Seidman A. College Student Retention: Formula for Student Success. West Port, CT: Praeger Publishers; 2005.

6. Bean JP. Dropouts and turnover: The synthesis and test of a causal model of student attrition. Res Higher Educ. 1980;12:155-187.

7. Bean JP. The application of a model of turnover in work organizations to the student attrition process. Rev Higher Educ. 1983;12:155-82.

8. Braxton JM, Brier EM. Melding organizational and interactional theories of student attrition: A path analytic study. Rev Higher Educ. 1989;13(1):47-61.

9. Tinto V. Dropout from higher education: A theoretical synthesis of recent research. Rev Higher Educ Res. 1975;45(1):89-125.

10. Tinto V. Leaving College. Rethinking the Causes and Cures of Student Attrition, 2e. Chicago: The University of Chicago Press; 1993.

11. Pascarella ET, Terenzini PT. Predicting freshmen persistence and voluntary dropout decisions from a theoretical model. J Higher Educ. 1980;51(1):60-75.

12. Lau LK. Institutional factors affecting student retention. Educ. 2003;124(1):126-36.

13. Tinto V. Research and practice of student retention: What next? J Coll Stud Retent. 2006;8(1):1-19.

14. Pascarella ET, Terenzini PT, Wolfle LM. Orientation to college and freshmen year persistence/withdraw decisions. $J$ Higher Educ. 1986;57(2):154-74.

15. Herzog VW, Anderson D, Starkey C. Increasing freshmen applications in the secondary admissions process. Athl Train Educ J. 2(Apr-Jan):67-73.

16. Young A, Klossner J, Docherty CL, Dodge MT, Mensch JM. Clinical integration and how it affects student retention in undergraduate athletic training programs. J Athl Train. 2013 (Jan/Feb):68-78. [PMID: 23672327]

17. Herzog VW. The Effect of Student Satisfaction on Freshman Retention in Undergraduate Athletic Training Education Programs (Doctoral dissertation) Retrieved from Proquest; 2004.

18. Glesne C. Becoming Qualitative Researchers: Anlintroduction, 4e. Boston, MA: Pearson Education, Inc; 2011.

19. Creswell JW. Mixed methods designs. In Smith P, Robb C (Eds.), Educational Research: Planning, Conducting, and Evaluating, Quantitative and Qualitative Research. Boston: Person Education, Inc; 2012: 534-75.

20. Esterberg KG. Qualitative Methods in Social Research. Burr Ridge, IL: The McGraw- Hill Companies, Inc; 2002.

21. Falk B, Blumernreich M. The Power of Questions: A Guide to Teacher and Student Research. Portsmouth, NH: Reed Elsevier, Inc; 2005.

22. Tinto V. Classrooms as communities: Exploring the educational character of student persistence. J Higher Educ. 1997;68(6):599-614.

23. Dodge MT, Mitchell FM, Mensch MJ. Student retention in athletic training education programs. J Athl Train. 2009;44(2):197-207. [PMID: 19295966]

24. Curtis N, Helion GJ, Domsohn M. Student athletic trainer perceptions of clinical supervisor behaviors: A critical incident study. J Athl Train. 1998;33(3):249-53. [PMID: 16558519]

25. Weidner GT, Henning MJ. Being an effective athletic training clinical instructor. Athl Ther Today. 2002;7(5):6-11.

26. Lofmark A, Thorkildsen K, Raholm MB, Natvig GK. Nursing students' satisfaction with supervision from preceptors and teachers during clinical practice. Nurse Educ Pract. 2012;12:164-9. [PMID: 22225731]

27. Mamchur C, Myrick F. Preceptorship and interpersonal conflict: A multidisciplinary study. J Adv Nurs. 2003;43(2):18896. [PMID: 12834377]

28. Rich JV. Clinical instructor's and athletic training student's perceptions of teachable moments in athletic training clinical education. J Athl Train. 2009;44(3):294-303. [PMID:19478843]

29. Christie NG, Dinham SM. Institutional and external influences on social integration in the freshmen year. J Higher Edu. 1991;62(4):412-34.

30. Kotecha M. Exploring nurse leaner wastage/persistence using a discursive approach: Towards a theoretical understanding of the subject. J Adv Nurs. 2002;40(2):210-7. [PMID: 12366651] 
Section I

\section{Appendix A Athletic Training Student Perception Survey}

Please answer the following questions as accurately as possible.

1. My high school grade point average (GPA) was out of $(4.0,4.5)$.

2. Age:

3. Sex: Male Female

4. Race: Caucasian

Hispanic

African American

Asian American

Native American

Other (please specify)

Section II

Please circle the most appropriate response.

3-Neutral 2-Disagree

1-Strongly Disagree

5. I am satisfied with my athletic training academic experience.

6. My athletic training clinical observation experiences have been interesting.

7. My athletic training clinical observation experiences did not meet my expectations.

8. It has been easy for me to interact with other observation students while at my clinical observation experience.

9. I feel I belong in this athletic training program.

10. I am confident that I have made the right decision in choosing this athletic training program.

11. My non-classroom experiences with the athletic training faculty has had a positive influence on my academic growth and interests.

12. I have some choice in how my clinical observation experiences are structured.

13. My athletic training clinical observation experiences have been challenging.

14. I am satisfied with the quality of my athletic training clinical instructors/preceptors.

15. I did not find the introductory course/s stimulating.

16. Since coming to this school, I have developed close personal relationships with other athletic training students.

17. It has been difficult for me to meet and make friends with other observation and athletic training students.

18. Overall, I am satisfied with my athletic training course of study.

19. It is very important for me to graduate from this athletic training program as opposed to some other program or school.

20. In my athletic training courses, I have performed academically as well as I anticipated I would.

21. My introductory course/s were engaging and stimulating.

22. It has been easy for me to meet and make friends with other observation students at my school.

23. My non-classroom experiences with the athletic training faculty have had an influence on my decision to apply or not apply to the program.

24. Program admission requirements have been communicated to me through multiple means (i.e., online materials, individual and/or group meetings.

25. Grades for assignments have been given according to published guidelines.

26. Goals and expectations of the pre-application period have

$\begin{array}{lllll}5 & 4 & 3 & 2 & 1 \\ 5 & 4 & 3 & 2 & 1 \\ 5 & 4 & 3 & 2 & 1 \\ 5 & 4 & 3 & 2 & 1 \\ 5 & 4 & 3 & 2 & 1 \\ 5 & 4 & 3 & 2 & 1 \\ 5 & 4 & 3 & 2 & 1 \\ 5 & 4 & 3 & 2 & 1 \\ 5 & 4 & 3 & 2 & 1 \\ 5 & 4 & 3 & 2 & 1 \\ 5 & 4 & 3 & 2 & 1 \\ 5 & 4 & 3 & 2 & 1 \\ 5 & 4 & 3 & 2 & 1 \\ 5 & 4 & 3 & 2 & 1 \\ 5 & 4 & 3 & 2 & 1 \\ 5 & 4 & 3 & 2 & 1 \\ 5 & 4 & 3 & 2 & 1 \\ 5 & 4 & 3 & 2 & 1 \\ 5 & 4 & 3 & 2 & 1 \\ 5 & 4 & 3 & 2 & 1 \\ & & & & \\ 5 & 4 & 3 & 2 & 1 \\ 5 & 4 & 3 & 2 & 1\end{array}$

(c) The Internet Journal of Allied Health Sciences and Practice, 2019 
been clearly communicated/explained to me.

27. I have input in program policies and procedures.

28. The published admissions requirements are fair and are an accurate representation of qualities needed to function as an athletic training student.

29. I understand why the pre-application process is in place.

30. It was difficult for me to understand all of the requirements to be eligible to apply to the program.

$$
\begin{array}{lllll}
5 & 4 & 3 & 2 & 1
\end{array}
$$

$\begin{array}{lllll}5 & 4 & 3 & 2 & 1\end{array}$

$\begin{array}{lllll}5 & 4 & 3 & 2 & 1\end{array}$

$\begin{array}{lllll}5 & 4 & 3 & 2 & 1\end{array}$

\section{Section III}

Please answer the following questions as it relates to experiences you have had up until your application decision. 31. If you were able to change anything about the structure of first semester, what would you change?

32. Please explain any particular experiences during your clinical observation experiences that were a strong influence on your decision to apply or not apply to the athletic training education program.

33. Please explain any particular experiences or interactions with other athletic training students or observation students that were a strong influence on your decision to apply or not apply to the athletic training education program.

34. Please explain any particular experiences during your athletic training introductory courses that were a strong influence on your decision to apply or not apply to the athletic training education program.

\section{Section IV:}

35. In my required classes for eligibility to apply, I must have a grade of or better.

36. I have applied to the athletic training education program.

37. To my knowledge, I met the minimum requirements to apply to the Athletic training education program.

Yes or No or Not Sure

38. Where there any other major factors that influenced your decision to apply or not apply to the athletic training education program? If so, please explain.

\section{Institution Demographics}

\section{Appendix B: Interview Questions for ATEP Directors/CECs}

Type of institution (private or public)

Size of institution.

Number of students

Program Demographics

How many students are currently enrolled in the required introductory courses

Type of introductory class/es (didactic psychomotor)

How many students typically apply?

How many students are typically accepted?

Admissions requirements

What is the typical size of the graduating class?

What is the GPA required for acceptance? Overall or Major? What is the numeric number?

What is the number of required introductory class/es and what are they?

What are the required grade/s students must obtain in the introductory class/es to be eligible for acceptance?

How many observation hours required?

Program Attributes

Are interviews required?

Communication

How are requirements communicated to observation students?

How are the goals and expectations of the pre-application period communicated to the observation students?

Participation in decision-making process

How are observation experiences determined or assigned?

Do observation students have input in this design? If so, how much input?

Do observation students have input in development of policies and procedures?

Perceived fairness in administration of policies and rules

How do you determine acceptance into the program?

Are acceptance procedures published for students?

How are grades determined in the introductory class/es? Have there been reported student concerns about how grades are calculated and given? 